\title{
Conservation Agriculture Promotion and Uptake in Mufulira, Zambia-A Political Agronomy Approach
}

\author{
Bridget Bwalya Umar ${ }^{1}$ \\ ${ }^{1}$ University of Zambia, Zambia \\ Correspondence: Bridget Bwalya Umar, University of Zambia, Zambia. E-mail: bridget.bwalya@gmail.com
}

Received: August 17, 2016

Accepted: October 20, 2016 Online Published: February 3, 2017

doi:10.5539/jsd.v10n1p156

URL: http://dx.doi.org/10.5539/jsd.v10n1p156

\begin{abstract}
This study utilized 120 semi-structured interviews with smallholder farming households and two focus group discussions; as well as several key informant interviews with experts to explore the promotion and uptake of conservation agriculture (CA) in Mufulira, Zambia. Results reveal that ridges and flat culture continued to be the preferred tillage systems ( 97 per cent and 55 per cent respectively) despite the farmers having been trained in the use of a minimum tillage technique. None of the interviewed farmers perceived CA as a solution to any of their agricultural related problems. The NGO promoting CA in the district had framed it as suited for and claimed to target labour constrained HIV/AIDS affected households. Conversely, farmers complained that CA was challenging for them due to its high labour demands ( 23 per cent); poor harvests (18 per cent) and was unsuited to the rainfall patterns of the area (10 per cent). Local agricultural experts contested the promotion of basins in Mufulira. The framing of CA as a solution to labour constraints did not seem to hold in the study area. This effectively limited the contestation spaces available to the public officials with dissenting views on the suitability of basin CA in the district.
\end{abstract}

Keywords: contested agronomy, smallholder farmers, minimum tillage, crop rotations, exotic goats, Heifer International

\section{Introduction}

\subsection{Agricultural Technology Promotions and Framing}

The low agricultural productivity of smallholder farming households in Sub Saharan Africa (SSA) has spurred the development and dissemination of agricultural productivity enhancing technologies from a range of actors. Adoption rates of these agricultural technologies have generally been low and were for a long time blamed on the conservatism of the targeted beneficiaries, the smallholder farming households. Increasingly there has been a recognition that the lack of uptake of agricultural technologies occurs because farmers are constrained in resources such that investment in a new technology not only influences what must be done in one field, but involves trade-offs with other activities from which the farmers generate their livelihoods (Giller et al., 2006). Some scholars have noted that the low adoption rates result from the promotion by agricultural experts of 'blueprint technologies' that are inappropriate and unsuited to smallholders for various economic or socio-cultural reasons. Actors engaged in agricultural development interventions choose and privilege specific agricultural technologies over others and promote these to smallholder households as scientifically proven to be the best technologies. The rhetoric around such technologies is framed in a way that conveys the message that the decisions to develop and disseminate particular technologies are made in apolitical environments without contestations. To frame, in Entman's words is to select some aspects of a perceived reality and to make them salient in a communicating text in such a way as to promote a particular problem definition, causal interpretation, moral evaluation, and/or treatment recommendation for the item described (1993: 52). Sumberg et al. (2013:77) assert that framing determines to a significant degree how much attention the problem receives and the approach taken to address it, and thus prefigures the eventual solution. In a similar vein, Tisenkopfs et al. (2014) explain that in framing, agents emphasize some aspects and downplay others, employing particular definitions and defining the scope of the issue.

Closely related to framing is the question of how agronomic research priorities are determined. While a large literature assumes that prioritization is (or should be) a rational, technical process, an alternative view sees it as a process in which power and politics are of utmost importance. Sumberg et al. (2013: 76) observed that there was 
'a tendency, supported by professional, institutional, business and political pressures, for powerful actors and institutions to attempt to "close down" or limit discussion in favour of particular research agendas and development pathways'. A result of this dynamic is the promotion of universal approaches to policy that obscure alternative framings and development pathways (Sumberg et al., 2012:11). This has been reported in cases of Integrated Pest Management (IPM), and Conservation Agriculture (CA).

Orr (2003) and Orr and Ritchie (2004) documented an IPM project in southern Malawi which was promoted on the basis of what turned out to be a wrong assumption that crop losses from pests and diseases were a critical constraint on smallholder crop production. Lessons learnt during the project were not implemented as this would have challenged the vested interests of the national research system and the donor agency (Orr \& Ritchie, 2004:48). Andersson and Giller (2012:1) outlined how CA became a policy success sanctioned by religion, despite earlier agronomic research suggesting the value of other options, evidence of disadoption and contestation over the suitability of particular CA technologies in Zimbabwe. This was a follow up on earlier critical analysis of CA in SSA by Giller et al. (2009) which had questioned whether CA was the best approach or whether its suitability for smallholder farmers in SSA had been established given their diverse settings. Both publications show a huge policy drive to promote $\mathrm{CA}$ in southern Africa by an array of organizations including the FAO, DFID, the EU, NORAD; international research and development organizations (CIMMYT, CIRAD, ICRAF and ICRISAT), and numerous NGOs that came about due to increased attention to CA in international policy discourse in the late 1990s and early 2000s and a shift in donor support from government-linked agricultural research to the NGO sector (Andersson \& Giller, 2012:2). This policy drive continued despite existence of scientific reports contradicting the claims of CA proponents. Why has the push for CA continued, and even intensified despite the persistent low adoption rates by its targeted beneficiaries, the smallholder farmers of SSA?

\subsection{Political Agronomy}

Sumberg and his colleagues $(2012,2013)$ are advocating for what they have termed 'political agronomy' when it comes to analysing agronomic issues. They have defined political agronomy as "the study of relationships and processes which link political, economic, and social forces and factors to the creation and use of agronomic knowledge and technology (2014:978). Political agronomy takes account of the contestation that can arise around the generation and promotion of new agronomic knowledge and technologies. This perspective is useful in analysing why some challenging ideas and innovations are successfully integrated into the agronomic research agenda while others are not (Sumberg et al., 2013: 77).

In their book contested agronomy - agricultural research in a changing world Sumberg and others discuss that new spaces of contestation have resulted from the arrival of new research actors and funders such as NGOs and other civil society organisations, and private agribusinesses. With the phenomenal development of the internet and other ICTs, websites have been set up through which information and experiences from a broad range of sources (peer and non-peer reviewed) are shared reflecting the interests of diverse communities, which include public relations units of research organisations, funders, development organisations and private firms promoting their scientific achievements and innovations. This development, they argue, means unsupported evidence and dubious conclusions can be widely propagated, and claims and counter claims about the impacts, outcomes and potentials of agronomic research technologies and practices may be partial and ill-informed. A political agronomy approach includes a concern for how legitimacy of research is determined, and how the presentation and interpretation of results supports or counters particular narratives and policy framings, or promotes particular political projects and agendas (2012: 9-10).

Political agronomy analysis can bring some important perspectives to the analysis of CA in southern Africa which has been the focus of much agronomic research and policy, and dissemination of technologies backed by a conglomeration of actors with diverse ideological backgrounds. This study uses political agronomy approach to analyse the implementation of CA in Zambia using a case study from a mining district. It differs from other studies of CA in Zambia, which are mostly apolitical, by explicitly focusing on the contestations surrounding the use of agronomic knowledge and technologies to promote an agenda that did not serve the interests of the targeted community and glossed over the contestations of stakeholders with alternative views.

\subsection{Conservation Agriculture in Zambia}

Conservation Agriculture has many definitions but there is a general consensus that its practice must encompass the simultaneous application of the three principles of (i) minimum or no mechanical soil disturbance (ii) permanent organic soil cover consisting of a growing crop or a dead mulch of crop residues, and (iii) diversified crop rotations or associations (Kassam et al., 2009). These principles are operationalized in many numerous 
ways by different actors which results in disparate technologies and practices being promoted under the umbrella term of CA. Thus conservation agriculture is not an actual technology but rather refers to a wide array of specific technologies and practices that are based on the simultaneous application of the three principles. A publication that was an outcome of a joint workshop organized by the Food and Agricultural Organization of the United Nations (FAO) and three agricultural organizations defined CA as a toolkit of agricultural practices that combines, in a locally adapted sequence, the simultaneous principles of reduced tillage or no-till; soil surface cover and crop rotations and/or associations, where farmers choose what is best for them (FAO, 2009:9). They elaborated that CA is essentially an approach that advocates the concept of sustainable intensification of production by picking the best possible options that farmers can apply at their own conditions.

CA as promoted in Zambia is packaged differently for the two distinct categories of target farmers; smallholder or commercial farmers. Smallholder farmers predominantly utilize manual or animal powered farming implements (hand held and ox-drawn); produce rain-fed crops for own subsistence and sale; and disproportionately use family labour in all farming operations. Traditional smallholder farming practices include complete soil inversion, shifting cultivation, burning of crop residues, and minimal use of external inputs such as hybrid seeds, herbicides and mineral fertilizers. Commercial farming is characterized by the use of motorized farm machinery, hybrid seeds, herbicides, mineral fertilizers, irrigation, hired labour, and modern management (Siegel \& Alwang, 2005). Smallholder farming households cultivate between less than one and up to 20 hectares of land, and constitute 92 per cent of the estimated 1,305,783 farming households in the country while the rest (8 per cent) are commercial farmers who till from 20 to 1000 hectares of land (Central Statistical Office [CSO], 2003).

The CA toolkit for smallholder farmers in Zambia contains several key practices and technologies. The key practices are dry-season land preparation using minimum tillage systems, retention of crop residues in the field, input application (seeds, mineral fertilizers, manure, and lime)in fixed planting stations or along ripped furrows, early and continuous weeding, leguminous crop rotations, and agro-forestry (CFU, 2006; 2009a, 2009b). For hand hoe farmers, use is made of a specially designed hoe-called a Chaka hoe- which is made of a one meter wooden handle and a relatively heavier blade. The Chaka hoe is used to make permanent planting basins which are supposed to be accurately measured. The recommended dimensions are $30 \mathrm{~cm}$ depth, $15 \mathrm{~cm}$ width, and $20 \mathrm{~cm}$ breadth, set out in a $90 \mathrm{~cm} \times 70 \mathrm{~cm}$ matrix (CFU, 2009a). For farmers using animal draught power, the oxen has attached to it a plough-like implement called a ripper. This is pulled behind the oxen to make furrows which are $15-20 \mathrm{~cm}$ deep and spaced 90-100 cm apart (CFU, 2009b).

Promotion of CA among smallholder farmers in Zambia has been on-going since the early 1990s. Development actors of various ideological persuasions have been involved and have differed in their agronomic practices preferred, in the incentives offered to adopters and pedagogically. Most organizations have engaged in CA promotion as part of broader programmes aimed at rural livelihood improvements and poverty reduction. These include the Conservation Society of Zambia and its COMACO (Community Markets for Conservation) Programme, DAPP (Development Aid from People to People), GART (Golden Valley Agricultural Research Trust), and the Ministry of Agriculture and Livestock.

In contrast the Conservation Farming Unit (CFU) was created in 1997 to exclusively promote CA in Zambia and has become the dominant player nationally and has made inroads regionally as well. CFU and most other actors in the promotion of $\mathrm{CA}$ in Zambia have restricted their activities to the low to medium rainfall regions. Concomitantly, CFU oversaw the development of the basin technology specifically tailored for low to medium rainfall areas, for capturing moisture and reducing the susceptibility of crops to intra-seasonal water stresses. Empirical evidence has shown that differences in yields from planting basins and traditional tillage methods are highest during seasons with below normal rainfall with planting basins showing a clear superiority (Langmead, 2004; Umar, 2011). Crops grown under CA are more drought tolerant (Grabowski and Kerr 2014). Conversely, during periods of above normal rainfall, the planting basins were waterlogged, which lead to reduced yields when remedial measures were not undertaken. Planting basins are thus unsuitable for high rainfall areas.

In 2013, The European Union (EU), FAO, and the Government of the Republic of Zambia (GRZ) launched a four year programme to increase crop production and productivity by 315000 smallholder farmers by promoting $\mathrm{CA}$ in nine out of Zambia's ten provinces. During the programme launch, the FAO representative contended that conservation agriculture had become a preferred means of promoting agricultural development for the 40per cent of rural population in Zambia who depend on agriculture for their survival; provides better resilience against droughts and prevents soil erosion (www.fao.org).This programme covers Zambia's high rainfall areas where the use of basin technology is likely to result in water logging and associated yield losses. One of the high rainfall areas in which basin technology based CA is being promoted is Mufulira town in the Copperbelt province of 
Zambia. In the rest of this paper I examine the promotion of CA in Mufulira using a political agronomy framework. Four research questions guided my study (i) What CA technologies/practices have been introduced and promoted? (ii) How was CA introduced (the process and the main actors) in Mufulira? (iii) What are the experiences of smallholder farmers and other actors concerning CA in Mufulira? The rest of the paper begins with a brief description of the study area, followed by the methods used for collecting and analyzing the data. This is followed by presentation of the results and discussion, and finally the conclusion.

\section{Method}

\subsection{Description of Study Area}

Mufulira town is located between latitudes $12^{\circ} 30^{\prime}$ South and $12^{\circ} 40^{\prime}$ South, and longitudes $28^{\circ} 10^{\prime}$ South and $28^{\circ} 20^{\prime}$ East (Figure 1). It experiences tropical savannah climate characterised by three typical seasons; hot and wet season from November to March; cool and dry season from April to July and; hot and dry season from August to October (Kapungwe 2013).

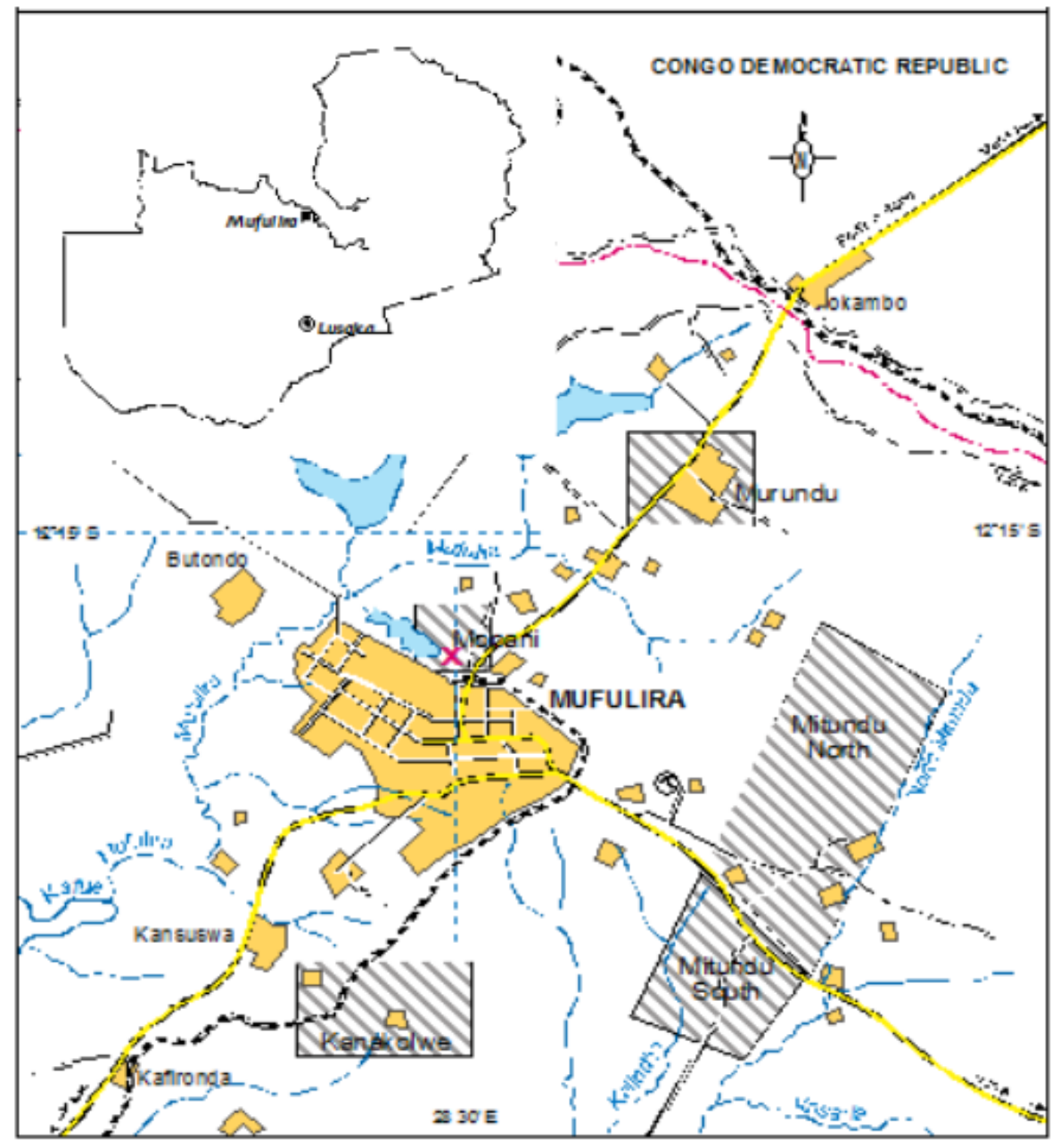

Figure 1. Map of MufuliraTown showing the study sites

The town is located in the high rainfall agro-ecological region which is part of the Central African Plateau. It received average annual rainfall of $1263.8 \mathrm{~mm}$ during the period 1969 to 2013. The minimum and maximum temperatures during the same period were 12 and $29{ }^{\circ} \mathrm{C}$ respectively (Zambia Meteorological Department, 2015). The high rainfall has resulted in highly leached, and consequently highly acidic sandy soils (Mutamba, 2007).The district is characterized by a crop growing period of 190 days (Kapungwe, 2013).

Mufulira's economy is dominated by copper mining. The town owes its genesis and growth to mining activities which started in 1932 and today include mining, smelting and refinery of copper; as well as other mining related industries and services. Agricultural activities are common in both its urban and peri-urban environs and are predominantly smallholder crop production. Smallholder crop production is mostly rain fed and is focused on 
crops such as maize (Zea mays), cassava (Manihot esculenta), groundnuts (Arachis hypogeae), sweet potatoes (Ipomoea spp), pumpkins and other cucurbits (Cucurbita spp), and African eggplant (Solanum macrocarpon). Some households own or lease agricultural plots near perennial streams and engage in irrigated production of vegetables during the dry season. Smallholder farmers use simple farming implements such as hand hoes and sickles. Livestock husbandry is minimal and mainly restricted to goats, pigs and rarely cattle. Collection and utilization of non-timber forest products is important among the peri-urban and rural households who appropriate firewood, mushrooms, tubers, fruits, bark rope, thatch grass, medicinal plants and bamboos. Farmers have relatively good linkages to stable urban markets due to the high population densities in the town and province at large, and proximity to other several highly urbanized mining towns.

The town shares borders with the Democratic Republic of Congo and is well connected by road to other mining towns in the province. The national census of 2010 projected the total population for the town to reach 161601 by 2014 and population density at 98.7 persons per $\mathrm{Km}^{2}$ (CSO, 2013). This is much higher than the national average population density of 17.3 and is due to the lure of the copper mine which has pulled people from other regions of the country into the district for over 80 years. There are no traditional structures (such as chiefs or head persons) and state structures control all facets of local governance. Much of the land in Mufulira is state land held under leasehold tenure (Note 1). Its residents are of mixed tribal groupings due to the historical migrations into the area but most of them speak ichibemba.

\subsection{Data Collection and Analysis}

Fieldwork for this study was conducted from June to August 2014. Semi structured interviews were conducted with 120 smallholder farmers from four communities, 30 from each community. The four communities were selected because CA had been promoted there since 2010 by the non-governmental organization, Heifer International Zambia under its 'Action on HIV and AIDS Nutrition and Food Security Project'. This project aimed at improving availability and access to sources of food and income for poor and vulnerable HIV and AIDS affected smallholder farmers (reference). This was to be achieved through the donation of exotic goats and training in CA to a selected sample of farming households in the study area. The households to be interviewed within the four communities were identified with the help of the local agricultural extension officers in conjunction with gatekeepers who had knowledge of the households that had participated in the Heifer International's CA project. A political analysis framework for conservation agriculture (Figure 2) was used for setting the questions to be asked to all the respondents and for analysis of responses. The framework was composed of a series of questions that drew attention to the framing of CA promotion, and possible sources of contestations among different actors in the agricultural sector. Respondents were asked the same series of questions and given considerable latitude in how they answered them, with follow up questions to clarify answers or get more information on issues that arose from their answers. The semi structured interviews were carried out by the author with the help of three research assistants in the local language.

Key informant interviews were conducted with agricultural and development experts and political leaders based in the town. The questions put to the experts included why and how CA was introduced into the town, who the main actors were, and the processes involved. Two focus groups discussions (FGDs) were conducted in two of the four study sites. The focus group discussants included both men and women farmers who had been trained in the use of CA technologies and those who had not received any training. The FGDs addressed issues related to planting basins, the use and availability of Chaka hoes, input use, weed management, and maize yields under CA. The responses from the semi structured interviews was typed into Microsoft Excel spreadsheet then copied to the qualitative data analysis software QDA Miner 3.2 (Provalis Research, 2010). Thematic analysis was used to systematically examine the answers to each question for themes and categories created to include the whole range of answers given to each question by all the respondents. Each response was then examined and placed in the relevant category. Frequencies and percentages were then calculated for each category. 


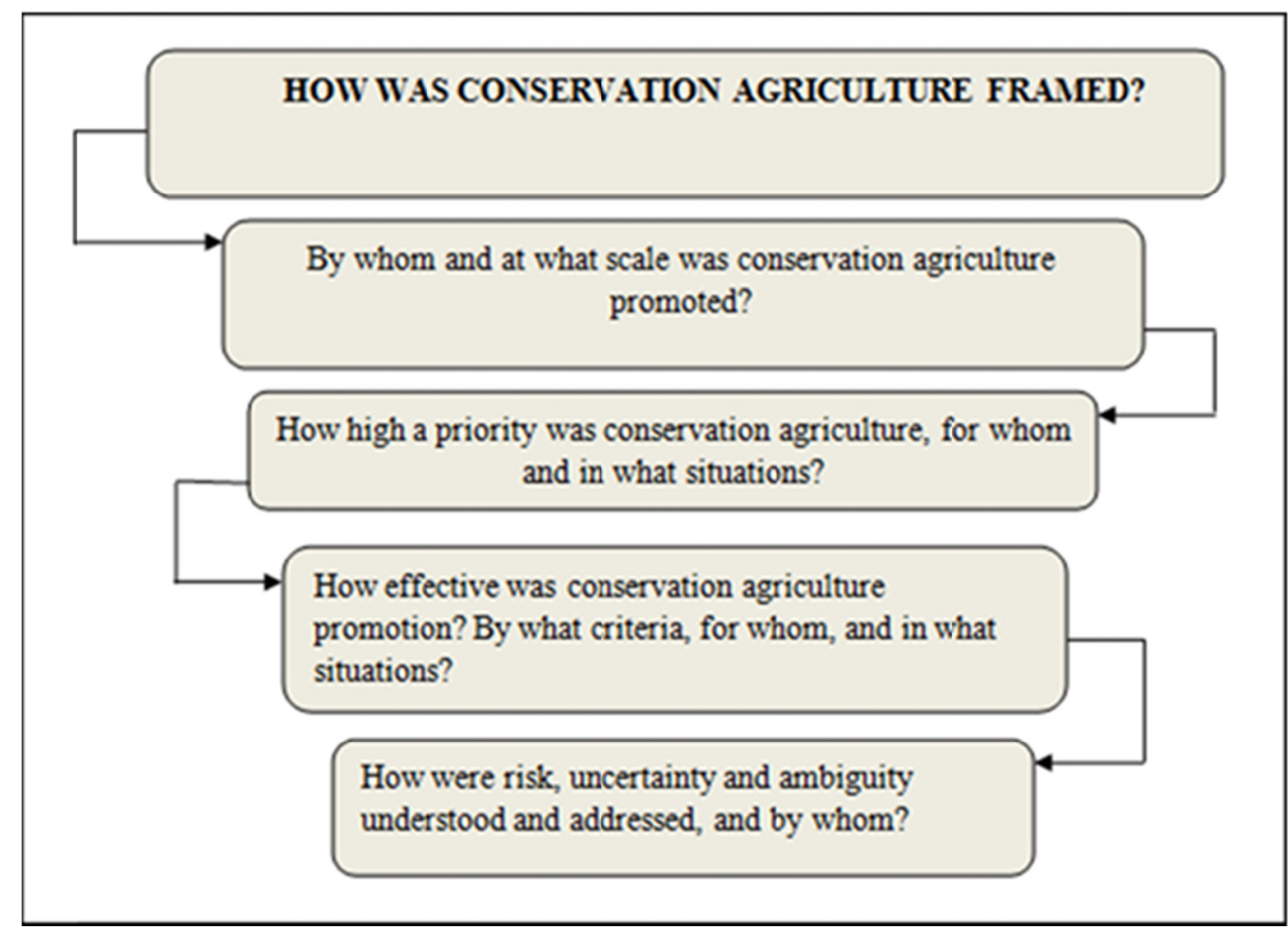

Figure 2. A political agronomy framework for conservation agriculture (after Contested Agronomy Conference 2016)

\section{Results and Discussion}

The mean household size for the sample was 7 with a mean of 3.5 members taking part in agricultural activities. The mean age of household heads was 54 years, and 70 per cent of the households in the sample were headed by men while the rest were women headed. The sampled households owned 6.2 hectares of land on average but only 41.4 per cent of this was under cultivation (mean cultivated size was 1.5 hectares).

\subsection{Experiences with Goat Project}

Livestock ownership was quite low with less than $1 \%$ of the sampled households owning cattle, 5 per cent owned pigs, 16 per cent owned goats and 71 per cent owned chickens. Several challenges were cited to explain the relatively low importance of livestock in the study area (Figure 2). Almost half of the respondents alluded to poultry diseases that have wreaked havoc on the free ranging chickens in the area. The poultry disease epidemics are common in the hot and dry season and have resulted in many of the sampled households losing all their chickens. 


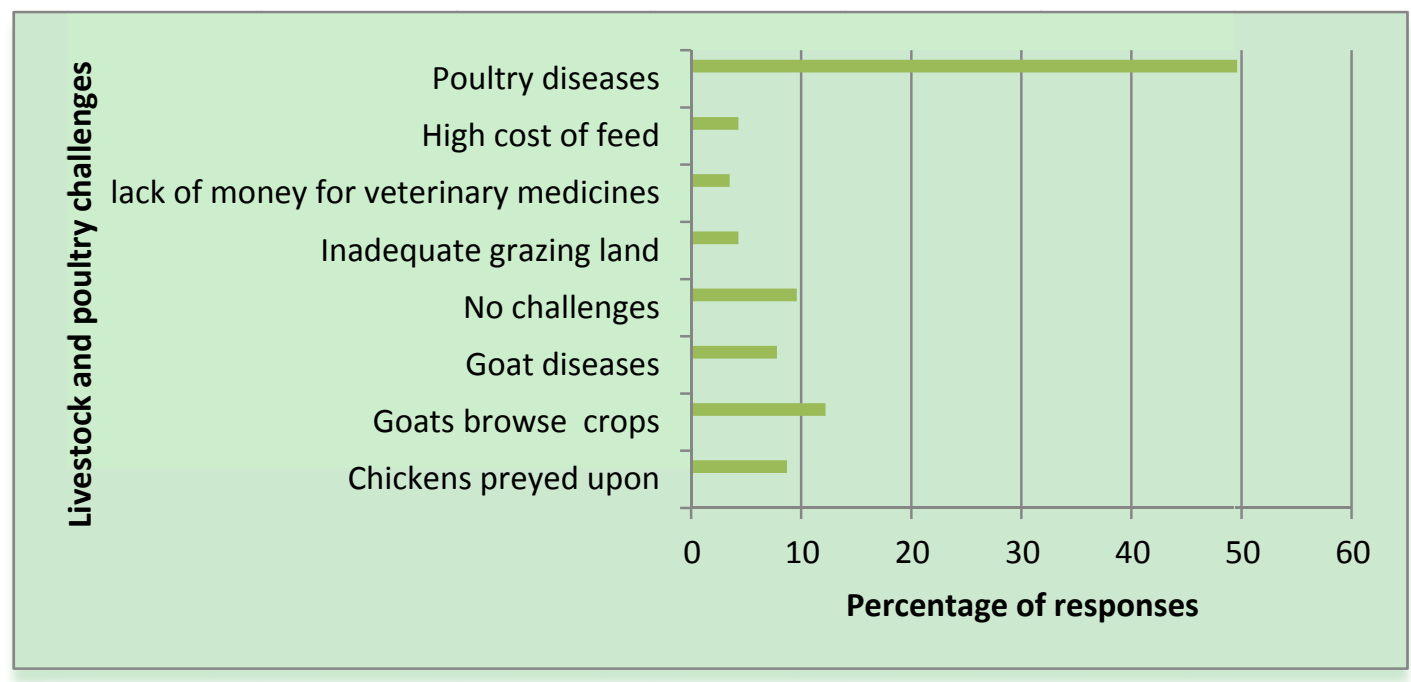

Figure 3. Livestock and poultry challenges faced by farmers in Mufulira, Zambia

For those that own goats, lack of grazing land which necessitates increased stall feeding has proved challenging. The lack of communal grazing areas means that once goats are let out of their shelters, they invariably end up browsing somebody's crops. Incidences of goat owners being fined were reported by both goat owners, and agricultural extension officers who are usually called upon to assess the economic value of the crop damage. The sampled households that owned goats had received them as gifts from Heifer International Zambia with a proviso to pass the gift on to others. Heifer International operates on the concept of 'passing on the gift'; a revolving fund in which one group of beneficiaries receives gifts of livestock from the NGO. The offspring of these animals are passed on as gifts to another group on the project. Time is given for the first generation to reproduce whose offspring are then passed on to the next group and so on. On average, passing on the gift lasts for at least nine generations, regardless of the project (Heifer International, 2015). The first beneficiaries reported that they have experienced many problems with their exotic goats as many of them were affected by several diseases, died and had to be replaced by the project. One respondent explained her experience as follows;

I received five goats from Heifer's Pass-on project. All the five goats from the first batch died due to diseases. The goats were not used to the local climate. They came from abroad so they easily succumbed to disease here. The project restocked the goats and now I have six [46 year old female farmer, goat project beneficiary, Murundu Area, July 2014]

Another respondent expressed the following views

These goats were sleeping on carpets where they came from. Now they are confused because the air has changed, that is why they are getting sick here.....they are Caucasians and thus susceptible to the diseases here [51 year old male, Local political leader and executive member of the goats projects committee].

The goat beneficiaries observed that they found it challenging to rear the goats due to the land tenure system in the area which does not have provision for communal grazing land. When they release their goats to range freely, they invariably end up in other people's fields and their owners have to compensate the crop owners. The alternative, which is full time stall feeding, was said to be too costly. Goat owners therefore have to always be on the lookout monitoring their goats' movements and ensure goat shelters are clean and the goats are given sufficient food. One respondent exclaimed the following in relation to this dilemma:

I am not interested in Heifer's goat rearing project. It is too demanding. Their exotic goats need constant monitoring which effectively reduces one to being a guard. Cases of goats browsing on crops in peoples' fields are common. This has discouraged me from taking part in the pass-on project [54 year old male Murundu farmer, July 2014].

All the goat owners referred to the challenge of diseases and upon being probed on how they addressed this challenge, they claimed that they had difficulties getting help from the public veterinary officers as they were met with "excuses" that there was no transport to enable them conduct field visits. It was alleged that veterinary 
extension officers demanded that the farmers meet the cost of fuel for their work supplied modes of transport (vehicle or motor cycle). This author interviewed key informants from the public agricultural sector in the town on the reported large incidences of goat diseases; procedures for the introduction of exotic livestock into new areas, and their roles in Heifer's goat project. The key informants observed that the district veterinary office was not notified about the introduction of the exotic goats, contrary to current state regulations. Regulations stipulate that importations of livestock can only be done after an import certificate has been issued. Once the livestock has been brought into the country, it has to be quarantined for a period of one month. The importer is responsible for securing quarantine structures, which have to be approved and routinely inspected by the district veterinary officer during the quarantine period. At the end of the quarantine period, the district veterinary officer is mandated to carry out tests on the livestock after which a certificate is issued. The district veterinary office in Mufulira reportedly had no idea about the number of goats that had been brought into the district; the breed and its likely disease challenges and were consequently not in a position to give sound goat husbandry advice to the affected goat farmers. One of the key informants complained as follows;

These NGOs just rush to do things because there is money. They ignore government regulations and ignore local government staff. I was called the other day by a business man who had been offered an exotic goat to buy by one of the beneficiaries. The beneficiaries are secretly selling off the goats and claiming they died. Yet before any livestock is sold and transported, a veterinary official has to be called in to certify it; same when there is death from disease. This is why livestock disease outbreaks are never ending in this country, because regulations are flouted [Interview with Key informant, $29^{\text {th }}$ January, 2015].

\subsection{CA Practices and Technologies-Local Experiences}

Ridges were the most common tillage system used, followed by flat culture (Table 1). Ridges were of two variants; the traditional large version and smaller ones locally known as 'agriculture' because they were introduced by the state's Department of Agriculture in the recent past. The 'agriculture ridges' are smaller than the traditional ones and were being used by $10 \%$ of the respondents.

Table 1. Tillage systems and reasons for their use in the study area

\begin{tabular}{|c|c|c|}
\hline Tillage System used & Reasons for using system & $\begin{array}{l}\text { Percentage of respondents } \\
\text { using tillage system }(n=120)\end{array}$ \\
\hline Ridges & $\begin{array}{l}\text { Easy to weed ( } 32 \%) \\
\text { Give good yields }(27 \%) \\
\text { Prevent crops getting waterlogged as } \\
\text { high rainfall in area (6\%) } \\
\text { Easier to make ridges than flat culture } \\
(17 \%) \\
\text { Suitable for certain crops }(12 \%) \\
\text { Retain nutrients as crop residues are } \\
\text { buried (3\%) } \\
\text { Easy to plant in ridges }(3 \%) \\
\text { Following local tradition }(7 \%)\end{array}$ & 96.7 \\
\hline Flat culture & $\begin{array}{l}\text { Good for groundnuts }(63 \%) \\
\text { Easier to weed }(5 \%) \\
\text { Yields higher than from ridges }(23 \%) \\
\text { Suitable for their soils }(3 \%) \\
\text { Facilitates herbicide use }(2 \%)\end{array}$ & 54.5 \\
\hline Planting basins & $\begin{array}{l}\text { On trial basis }(29 \%) \\
\text { Prevents fertilizer run-off }(6 \%) \\
\text { Keeps soil fertile }(12 \%)\end{array}$ & 14 \\
\hline
\end{tabular}


Weeding retains soil near crop roots

$(6 \%)$

Reduces labour needs $(6 \%)$

Higher crop density $(6 \%)$

What we have been taught to use $(6 \%)$

The figures in parentheses represent the percentages among those who used the tillage system that expressed the view.

Flat culture which involves complete turning of soil using a hand held hoe was used by about 55 per cent of the sample and mostly for groundnuts; and on virgin land. The respondents reported that this is the only suitable method for cultivating groundnuts in the area and is used despite its higher labour demands compared to making ridges. Basins were used by 14 per cent of the sampled households. For the entire sample, 27 per cent of the households had tried and disadopted CA while 60 per cent had never tried it on their individual plots despite having been trained in the use of CA technologies and practices. Most of the respondents had tried CA by testing it on group or demonstration plots. It is common practice for farmers in the study area to belong to a farmers group and attend training sessions in groups. These are the groups that were targeted for trainings in $\mathrm{CA}$. The groups then tried out the CA practices on a quarter hectare plot for a complete season after which members were expected to move to individual plots. After the group trials, almost $60 \%$ made up their minds not to try CA on individual plots while $27 \%$ tried it but discontinued. They explained that several bottlenecks hindered their fully fledged adoption of CA (Table 2). This seems to suggest that the CA promotion had not been very effective as the majority of the farmers trained in the use of CA technologies and practices did not adopt it at household level.

Table 2. Bottlenecks to adoption of conservation agriculture in study area

\begin{tabular}{lc}
\hline Bottlenecks to CA adoption & Percentage of responses \\
\hline Basin digging too labour intensive & 24.3 \\
Difficulties in accessing CA equipment and inputs & 23.4 \\
Poor harvests & 17.8 \\
Basins unsuited to high rainfall & 10.3 \\
Weed burden/pressure too high & 9.3 \\
Insufficient knowledge on CA & 5.6 \\
Drudgery of precise measurements in CA & 4.7 \\
Increased termite attacks & 2.8 \\
Chaka hoe is too heavy for women & 1.9 \\
\hline
\end{tabular}

The making of planting basins was reported as being very hard work. The need for precisely measuring the dimensions of basins using ropes, and bottle tops; and application of accurately measured out lime, mineral fertilizer, manure and seed added to the drudgery. CA promoters had encouraged the farmers to spread out the work of making basins by commencing in the dry season rather than the conventional practice of waiting for the commencement of seasonal rains before starting land preparation. The farmers noted that this practice was unsuited in a high rainfall area like theirs because after the onset of the rains, the already made basins were overrun by weeds by the time they were ready to sow their crops. They further explained that with the high rainfall, the basins were easily waterlogged resulting in reduced yields and poor harvests. Thus although the CA promoter had framed CA as cardinal for labour constrained farming households, this view was not shared by the respondents.

Most complained about the stunted maize that gave poor harvests. Thus unlike in the low rainfall regions of Zambia, in the study area, CA is a system associated with lower yields. One farmer put this view across as follows: 
I stopped conservation agriculture due to excessive labour demands and bad harvests. I could start if weed killer will be ready, given to me for free as its expensive to buy. No conservation agriculture without weed killer [40 year old female farmer, Murundu July 2014].

Another farmer expressed the following views on why he disadopted CA

I disadopted conservation agriculture due to poor harvests after heavy rainfall. I have no intentions of re-starting conservation agriculture because the rainfall is just too much for the practice of conservation agriculture [70 year old male farmer, Murundu July 2014]

Hiring labour for making basins was more expensive for a given area compared to ridges, and was reportedly less profitable given that "maize yield levels from the waterlogged basins were very low". Key informants from the district agricultural office were interviewed about why the practice of making basins was being promoted in the town, when it seemed that it was agronomically unsuited. This author was informed that the district office encouraged other CA practices such as crop rotations, improved efficiency in input application but not the making of basins. Actors involved in the promotion of basins had not formally consulted the district agricultural department. Thus for the public sector experts, CA was not a high priority in the agricultural development agenda for the district.

The key informant from Heifer International explained that the organization had promoted CA and basins in particular in the study area based on recommendations from a consultant that basins would ease the work load of HIV and AIDS affected households. The organization trained 137 farmers and provided them with seeds, Chaka hoes, and teren ropes for demonstration purposes. The seeds provided were for the leguminous crops sun hemp (Crotalaria juncea), velvet beans (Mucuna pruriens) and pigeon peas (Cajanus cajan). The organization reportedly found it difficult to implement other CA technologies and subsequently evaluate which were the most appropriate for Mufulira due to the short duration of the project. When asked about the organization's experience with basins, the key informant said "the basins only did well in 2010/2011 season when we had moderate rains. In 2011/2012 season they did not do very well and farmers were advised to cover them a bit". In this way, attempts were made to address the hazard of water logged basins by making small ridges around the standing crops, which is what is conventional done in the area.

The farmers alluded to the unavailability of CA implements and inputs. Several explained that they could not continue with CA because they did not have all the required implements and inputs. There was a perception that the practice of CA necessitated too many inputs which had to be available at the right time and in right quantities. The Chaka hoe was cited as especially difficult to access as it is not available for sale locally but only accessible through the project. The need to have all the inputs mandatory for CA practice in order to start is in sharp contrast to what farmers do with conventional farming practices. In addition, the farmers seemed reluctant to dedicate their own inputs to the practice of CA but seemed to prefer that somebody else, preferably CA promoters meet these costs. Sentiments such as " if I am provided with inputs, I will start conservation agriculture " or " they [CA promoters] did not bring the inputs as promised so we did not start conservation agriculture". They seemed unwilling to use own inputs in testing the new agricultural system. Thus for most, adoption of CA was premised on receiving free inputs as incentives. In a way, the risks associated with CA adoption were expected to be borne by the CA promoter. In response, the CA promoter supplied free agricultural inputs and implements needed for correct practice of CA to the targeted farmer groups. It was incumbent upon the CA promoter to sort out the ambiguities associated with CA, if farmers were to adopt it.

The provision of incentives to spur adoption or participation is now a pervasive feature of development interventions in Zambia. Project beneficiaries have become accustomed to being given material incentives for them to partake in development interventions. Project implementers work with local gatekeepers to identify and organize beneficiaries. For agricultural projects, the farmer cooperatives are used as they are already organized and registered entities. Farmer cooperatives have been formed to fulfil the Ministry of Agriculture pre-condition for accessing subsidized farming inputs from the state. Farmer cooperatives are selected or agree to take part in projects depending on their perceived usefulness to their members. When it is thought that benefits could be obtained for members that in some way improve their overall welfare, cooperatives take part in development interventions whose goals they may not necessarily agree with. In this study, I found that most cooperative members did not think basins could ever work well in the area but they went for trainings in the hope that they could access hybrid seed, lime and fertilizer which they could use to sow larger areas of their agricultural plots. 
Focus group discussants agreed that they did not think CA and the goat project addressed their pressing challenges as farmers and did not provide the kind of assistance that they were most in need of. Results from the household semi-structured interviews show that access to mineral fertilizers, and hybrid seed was the most frequently reported form of assistance the respondents would like to receive (Figure 2). Over three-quarters want access to (more) subsidized hybrid seed and mineral fertilizer. Those already receiving seed and fertilizer subsidies called for larger quantities and to be delivered on time. In the recent past the subsidized inputs have been delivered late. This resulted in late sowing and concomitantly reduced yields. Subsidy recipients also complained of receiving expired hybrid seeds which failed to geminate, and receiving top dressing fertilizer (which is to be applied when the maize stalks are at knee height) at time of planting and only receiving the basal fertilizer (which requires pre-emergence application) when it is too late to use it as it is delivered when the maize has already germinated.

Farmers also requested for assistance with tractors and other mechanized machinery to help lighten labour demands, especially during land preparation and weeding.

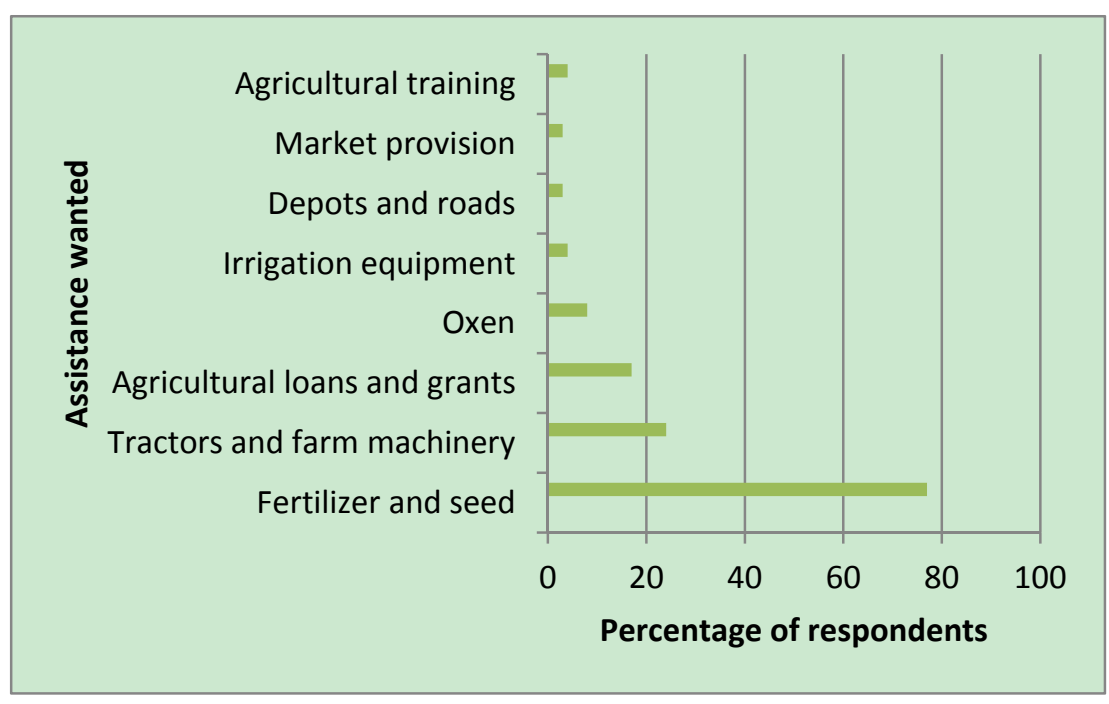

Figure 4. Assistance wanted by farmers in study area

The major bottlenecks to enhancing agricultural productivity seems to be labour shortages during land preparation and weeding given the short period in which these activities have to be performed. The use of oxen, tractors and herbicides significantly reduces manual labour demands which are met by household members and occasionally hired labourers. Most farmers are engaged in irrigated vegetable farming and would like to expand their operations. For this they require pumps and other equipment. Farmers in two of the four study sites are renowned for their vegetable gardens and supply the bulk of the vegetables sold in all the markets in the town and beyond. Their proximity to highly urbanized areas with high population densities, good road connections and existence of several perennial streams has provided them with a comparative advantage not available to their more rural based counterparts.

Mufulira town is a high rainfall area and receives some of the highest annual amounts of rainfall nationally (Zambia Meteorological Department 2015). About 11 per cent of the interviewed farmers observed that their area received too much rainfall, which caused their fields to become waterlogged. Five per cent noted that the rainfall distribution has been variable in the last several years with late onset and early end to season. The rest of the respondents (74 per cent) had not experienced any rainfall challenges and thought the area received more than adequate rainfall for proper crop development. This further suggests the inappropriateness of basins which have been developed essentially as a water harvest technology for low rainfall areas. Development interventions that aim at addressing such farmer identified challenges would probably spur more spontaneous adoption.

By working with already established groups, project implementers failed to reach non-group members. The Action on HIV and AIDS Nutrition and Income Project is said to have targeted HIV/AIDS affected vulnerable households yet in its selection of beneficiaries to be trained in the use of CA technologies, the criterion used was membership to a farmer cooperative. It is difficult to see how targeting farmer cooperatives would result in helping labour constrained HIV/AIDS affected households improve their nutrition and incomes, as advanced by 
the project rhetoric. In addition, promoting basins among labour constrained households as a labour saving technology seems inimical to project goals given that basin making demands high labour inputs. During interviews with women farmers and FGDs, sentiments were expressed on how women found it especially challenging to use Chaka hoes, and how basin making exacerbated their labour constraints. Recent research has shown that basin making does not reduce labour inputs compared to conventional manual based tillage systems (Andersson 2011; Umar 2012; Rusinamhodzi 2015). This seems to suggest that the privileging of basins over other tillage systems as a labour saving technology did not result from empirically based evaluations.

This leads to the question of why the promotion of CA in this project was privileged over other agricultural systems. Over the past decade CA has arguably become a hegemonic paradigm in scientific and policy thinking about sustainable agricultural development (Andersson \& D'souza, 2014:116). In the last few years, it evolved from being framed only as a sustainable agricultural intensification option to climate smart agriculture (CSA). As CSA, it is advocated as an important option for smallholder farmers in SSA in responding to climate variability and climate change. With the increased visibility of climate change in discourses or 'climate washing' among international development agencies, many NGOs have jumped onto the bandwagon and added CA to their repertoire of development interventions. This has seen CA being promoted in many diverse environments to smallholder farmers as a response to climate change without considerations given to its suitability to the bio-physical and socio-economic conditions of their environments. The example provided in this study shows interventions framed as uncontested and apolitical efforts whose only goal was to help various selected groups of vulnerable people. Contestations or dissenting views were variously downplayed or downright ignored. The decision to implement basins proceeded despite dissenting views from local agricultural experts and while the introduction of exotic goats was achieved by ignoring national veterinary regulations.

\section{Conclusion}

This study shows the relatively unsuccessful attempt to introduce conservation agriculture in Mufulira, Zambia by an international NGO amid contestations from local agricultural experts on the suitability of some conservation agriculture technologies to the local climatic conditions and labour availability. Labour constrained households complained about the high labour demands of basin technology even as the technology promoters hailed it as especially suited for and targeted at HIV/AIDS households who were framed to have the most severe labour constraints. The supply driven promotion of goat rearing was not preceded by a rational technical process of evaluating the suitability of introducing the exotic breeds into the new environment. Reports of introduced goats succumbing to diseases were common among the goat project beneficiaries while the local veterinary officers were handicapped to provide services as they had not been made privy to the goat project as required by national veterinary regulations. The short duration of the conservation agriculture and goat project did not provide sufficient time for learning and incorporation of lessons learnt so as to better tailor the interventions to local context and aspirations of project beneficiaries.

The effect of this experience on the community is increased negative perceptions towards development interventions which could limit their participation in such endeavours in future. The use of the political agronomy framework has enabled the consideration of contestations among the various development actors involved in agricultural development initiatives in the district and shown the important role that vested interests play in privileging one set of factors other others. It is important to pay attention to such contestations as they influence the success of proposed agricultural initiatives at present and in the future, and their explicit consideration could provide for space for alternative interventions and higher chances of their success.

\section{Acknowledgments}

This publication is part of the author's research work at Umeå University, thanks to a Swedish Institute Post-Doctoral Guest Researcher Scholarship.

\section{References}

Andersson, J. A., \& D'Souza, S. (2014). From adoption claims to understanding farmers and contexts: A literature review of Conservation Agriculture (CA) adoption among smallholder farmers in southern Africa. Agriculture, Ecosystems \& Environment, 187(0), 116-132. http://dx.doi.org/10.1016/j.agee.2013.08.008

Andersson, J. A., \& Giller, K. E. (2012). On heretics and God's blanket salesmen: Contested claims for conservation agriculture and the politics of its promotion in African smallholder farming. Contested Agronomy: Agricultural Research in a Changing World. J. Sumberg, Thompson, J. London, Earthscan.

Andersson, J. A., Giller, K. E., Mafongoya, P., \& Mapfumo, P. (2011). Diga-Udye or Diga-ufe? (Dig-and-eat or Dig and die): Is Conservation Agriculture Contributing to Agricultural Involution in Zimbabwe? Regional 
Conservation Agriculture Symposium for Southern Africa. Johannesburg South Africa, FAO Regional Emergency Office for Southern Africa.

CFU. (2006). Reversing Food Insecurity and Environmental Degradation in Zambia through Conservation Agriculture. Lusaka, Conservation Farming Unit.

CFU. (2009a). Conservation Farming and Conservation Agriculture Handbook for Hoe Farmers in Agro-Ecological Regions I and IIa-Flat Culture. 2009 Edition. Lusaka, Conservation Farming Unit.

CFU. (2009b). Conservation Farming and Conservation Agriculture Handbook for Ox Farmers in Agro-Ecological Regions I and IIa. 2009 Edition. Lusaka, Conservation Farming Unit.

CSO. (2003). Zambia 2000 Census of Population and Housing. Agriculture Analytical Report. Lusaka, Central Statistical Office.

CSO. (2013). 2010 Censu of Population and Housing. Population and Demographic Projections 2011-2035. Lusaka, Central Statistical Office.

Entman, R. M. (1993). Framing: Toward Clarification of a Fractured Paradigm. Journal of Communication, 43(4), 51-58. http://dx.doi.org/10.1111/j.1460-2466.1993.tb01304

Giller, K. E., Rowe, E. C., de Ridder, N., \& van Keulen, H. (2006). Resource use dynamics and interactions in the tropics: Scaling up in space and time. Agricultural Systems, 88(1), 8-27. http://dx.doi.org/10.1016/j.agsy.2005.06.016

Grabowski, P. P., \& Kerr, J. M. (2014). Resource constraints and partial adoption of conservation agriculture by hand-hoe farmers in Mozambique. International Journal of Agricultural Sustainability, 12(1), 37-53. http://dx.doi.org/10.1080/14735903.2013.782703

Heifer International. (2015). The Heifer Way. Big change starts small. Retrieved February 26, 2015, from http://www.heifer.org/ending-hunger/the-heifer-way/index.html

Kapungwe, E. M. (2013). Heavy metal contaminated water, soils and crops in peri-urban wastewater irrigation farming in Mufulira and Kafue towns in Zambia. Journal of Geography and Geology, 5(2), 55-72. http://dx.doi.org/10.5539/jgg.v5n2p55

Kassam, A., Friedrich, T., Shaxson, F., \& Pretty, J. (2009). The spread of Conservation Agriculture: justification, sustainability and uptake. International Journal of Agricultural Sustainability, 7(4), 292-320. http://dx.doi.org/doi:10.3763/ijas.2009.0477

Langmead, P. (2004). Hoe Conservation Farming of Maize in Zambia. Lusaka.

Mutamba, M. (2007). Farming or Foraging? Aspects of Rural Livelihoods in Mufulira and Kabompo Districts of Zambia. Bogor, Center for International Forestry Research.

Orr, A. (2003). Integrated Pest Management for Resource-Poor African Farmers: Is the Emperor Naked? World Development, 31(5), 831-845. http://dx.doi.org/10.1016/S0305-750X(03)00015-9

Orr, A., \& Ritchie, J. M. (2004). Learning from failure: smallholder farming systems and IPM in Malawi. Agricultural Systems, 79(1), 31-54. http://dx.doi.org/10.1016/S0308-521X(03)00044-1

Provalis Research. (2009). QDA Miner Version 3.2. Montreal, Provalis Research.

Rusinamhodzi, L. (2015). Tinkering on the periphery: Labour burden not crop productivity increased under no-till planting basins on smallholder farms in Murehwa district, Zimbabwe. Field Crops Research, 170(0), 66-75. http://dx.doi.org/10.1016/j.fcr.2014.10.006

Siegal, P. B., \& Alwang. J. (2005). Poverty reducing potential of smallholder agriculture in Zambia: Opportunities and Constraints. Africa Region Working paper Series No. 85. Washington, D.C, The World Bank.

Sumberg, J., Thompson, J., \& Woodhouse, P. (2012). Contested agronomy: Agricultural research in a changing world. Contested agronomy: Agricultural research in a changing world. J. Sumberg, Thompson, J. London, Earthscan.

Sumberg, J., Thompson, J., \& Woodhouse, P. (2013). Why agronomy in the developing world has become contentious. Agriculture and Human Values, 30(1), 71-83. http://dx.doi.org/10.1007/s10460-012-9376-8

Tisenkopfs, T., Kunda, I., \& Sumane, S. (2014). Learning as Issue Framing in Agricultural Innovation Networks. The Journal of Agricultural Education and Extension, 20(3), 309-326. 
http://dx.doi.org/10.1080/1389224X.2014.887759

Umar, B. B., Aune, J. B., Johnsen, F. H., \& Lungu, I. O. (2012). Are Smallholder Zambian Farmers Economists? A Dual-Analysis of Farmers' Expenditure in Conservation and Conventional Agriculture Systems. Journal of Sustainable Agriculture, 36(8), 908-929. http://dx.doi.org/10.1080/10440046.2012.661700

Umar, B. B., Aune, J. B., Johnsen, F. H., \& Lungu. O. I. (2011). Options for Improving Smallholder Conservation Agriculture in Zambia. Journal of Agricultural Sciences, 3(3), 50-62. http://dx.doi.org/10.5539/jas.v3n3p50

Zambia Meteorological Department. (2015). Monthly Rainfall Records. Lusaka, Zambia Meteorological Department.

\section{Notes}

Note 1. Zambia has a dual land tenure system; customary and statutory. Customary land is controlled by the chiefs and their village heads but act with the consent of their people and govern according to local customary practices. Statutory land is held under leasehold tenure.

\section{Copyrights}

Copyright for this article is retained by the author(s), with first publication rights granted to the journal.

This is an open-access article distributed under the terms and conditions of the Creative Commons Attribution license (http://creativecommons.org/licenses/by/4.0/). 